\title{
Pheochromocytoma and Paraganglioma cM1c TNM Finding v8
}

National Cancer Institute

\section{Source}

National Cancer Institute. Pheochromocytoma and Paraganglioma CM1c TNM Finding v8. NCl Thesaurus. Code C141112.

Distant metastasis to bone plus multiple other sites. (from AJCC 8th Ed.) 